\title{
Soot Blowing Operation Optimization Using PSO Method by Studying Behaviour of Operating Parameter in Sub Critical Coal Fired Power Plant
}

\author{
Taneshwaren Sundaram ${ }^{1, *}$, Firas Basim Ismail ${ }^{1}$ and Pogganeswaren Gurusingam ${ }^{1}$ \\ ${ }^{1}$ Power Generation Unit, Institute of Power Engineering (IPE), Universiti Tenaga Nasional, 4300, \\ Kajang, Selangor, Malaysia
}

\begin{abstract}
Coal, natural gas and fuel-oil are three major fossil fuels sources are vastly used in electrical power generation sector in Malaysia. In a coal fired power plant, the major byproducts resulting from coal combustion inside boiler is soot, ash and NOx emissions. Boiler fouling and slagging are common problems that leads reduces heat transfer rate in furnace and boiler efficiency. This happens when soot and ash is formed and deposited along the boiler tubes, furnaces and heaters. Hence, soot blowing operation is used to blow off steam in affected areas of boilers as a cleaning mechanism. However, current soot blowing operation is practiced through operator's visual inspection of slagging or fouling rate in furnace. This leads to inefficient soot blowing operation that effects the plant's operating and maintenance cost. Thus, by studying behavior of operating parameters, soot blowing operation can be optimized to reduce unnecessary soot blowing operation in power plant.
\end{abstract}

\section{Introduction}

Soot, ash and slag are main byproducts of combustion process in a coal fired power plant. These byproducts plays an important role that effects boiler efficiency. Generally, large combustion deposits inside boiler decreases the boiler efficiency. To maintain optimum boiler efficiency, soot blowers are operated periodically to clean boiler surfaces. Steam is used as a medium to blow of boiler flue gas circuit at different points. Periodic cleaning is done to boiler parts that are easily exposed to ash deposits such as furnace, super-heater, reheater and economizer. However, there is no efficient ways in utilizing the soot blowing operation to enhance the performance of the boiler. For instance, for insufficient soot blowing, the transfer of heat from flue gas to steam is impeded that causes the boiler efficiency to decrease. These results in large soot deposits that require additional fan power that will further reduce the efficiency. Besides that, too frequent cleaning causes heating surface erosion and related unit outages as increased spray flow reduces the efficiency of the boiler. An optimized soot blowing operation ensures soot blowers function when it is needed

\footnotetext{
* Corresponding author : tanesh722@live.com.my
} 
and in necessary location. [1, 2]. Besides, soot accumulation monitoring system provides data that initiates soot blowing operation during boiler operations [3, 4]. A tool to predict and measure soot accumulation in boiler is studied by taking account of numerical data. Soot accumulation in affected areas triggers the soot blowing operation based on plant data. Soot blowing operation will be activated based on studying and optimizing boiler parameters. The contribution to this work is to reduce the frequency of soot blowing that result reducing the steam consumption during soot blowing that will eventually increase the efficiency of boiler and reduce maintenance cost [5].

\section{Methodology}

The methodology is built based on the research made on most related works in literature review. There are three main phases that is constructed in this methodology are as follows:

Data Preparation $>$ Modelling $>$ Analysis and Discussion

\subsection{Data Preparation}

In this phase, the most important part is to identify and characterize each plant data. All the necessary data is taken from the Plant Information (PI) station in TNB Janamanjung. With advice from plant engineers, soot blowing operation parameters are chosen and analysed accordingly. The parameters are chosen based on steam water, air/flue and fuel data from the system.

\section{Variable Behavioural Study}

All the variables of soot blowing operation is studied and analyzed in order to get a clear picture on how parameters are being affected by soot blowing condition. In Figure 1, the straight line indicates soot blowing operation. Soot blowing happens when steam from outlet press is about 40 bar. The dotted line indicates how variables correlate to soot blowing sequence interval. All variables are studied to find coherence between soot blowing operation and how variables behave accordingly. In Figure 1, we can observe boiler efficiency increases slightly as soot blowing operation takes places. At 40 bar steam pressure, most of boiler efficiency points are increasing in time.

\section{Soot Blowing Operation againts Boiler Efficiency}

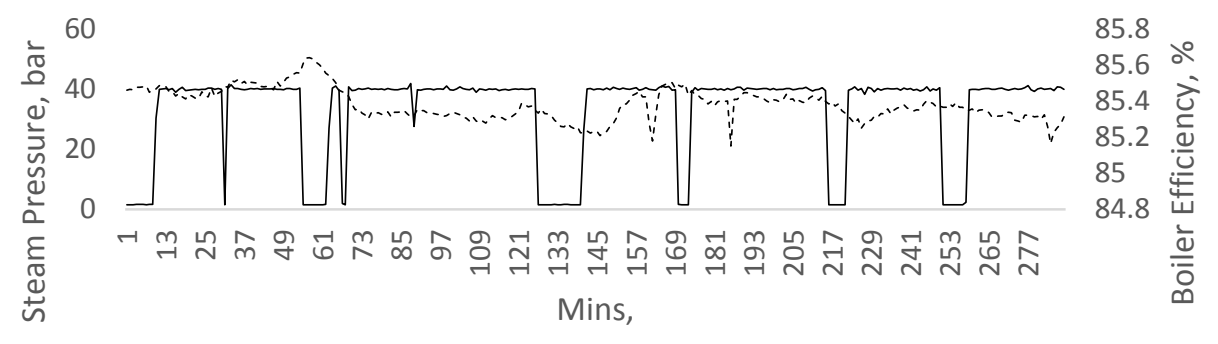

Figure 1. Graph of Soot Blowing Sequence against Boiler Efficiency 


\subsection{CFD Modelling}

Modelling a real time boiler is poignant in determining the characteristics of each boiler parameters. ANSYS V15 is used in CFD to simulate boiler condition with presence of soot [6]. The main objective of this simulation is to study each boiler parameters and how it is effected by soot blowing operation. A pre-modelled boiler is used to simulate boiler conditions with $500-1000$ iterations with boiler operating conditions shown in Table 1. For coal combustion modelling, a discrete phase model (DPM) was used to solve the transport equations for the continuous phase.

Table 1. Boiler Operating Conditions

\begin{tabular}{|l|l|}
\hline Case description & Operating conditions \\
\hline $\begin{array}{l}\text { Total flow rate of total primary air }(\mathrm{km} 3 / \mathrm{h}) \\
\text { and temperature }(\mathrm{K})\end{array}$ & 600 and $300 \mathrm{~K}$ \\
\hline $\begin{array}{l}\text { Total flow rate of total secondary air } \\
(\mathrm{km} 3 / \mathrm{h}) \text { and temperature }(\mathrm{K})\end{array}$ & 600 and $550 \mathrm{~K}$ \\
\hline Total coal feed rate $(\mathrm{t} / \mathrm{h})$ & 360 \\
\hline
\end{tabular}

Soot model is given as One Step Modal (Khan and Greeves) is chosen whereby single transport equation for soot mass fraction is modelled as shown in Table 2.

Table 2. Soot Model

\begin{tabular}{|l|l|}
\hline Parameter & Process value \\
\hline Stoichiometry for soot combustion & 2.6667 \\
\hline Stoichiometry for fuel combustion & 3.6363 \\
\hline $\begin{array}{l}\text { Activation temperature for soot formation } \\
\text { rate }(\mathrm{K})\end{array}$ & 1700 \\
Magnussen Constant for Soot Combustion & 4 \\
\hline
\end{tabular}

A finite volume method was chosen since most of fossil fuel combustion simulations applied this type of method. SIMPLE-based approach was used for pressure-velocity coupling scheme. The solution was simulated until convergence is achieved.

\section{Results and discussion}

\subsection{Boiler modal behaviour analysis}

Through analysis using Computational Fluid Dynamics (CFD), the factors that has been considered in soot blowing has been taken into account and simulated using this software. 


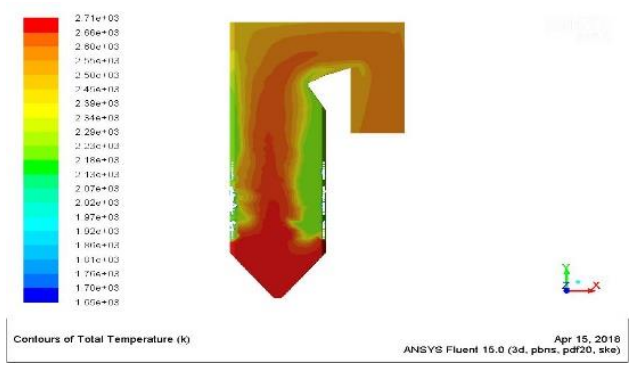

Fig. 2. Contours of Total Temperature

When soot blowing happens, the boiler is assumed as a clean boiler. [7] When the fireball is formed and flue gas is produced, soot accumulation and slagging will take place in boiler. In Figure 2, the green shady green area is simulated to be area which has lower temperature region at $2130 \mathrm{~K}$ compared to region in the middle of the boiler which simulates temperature reading around $2700 \mathrm{~K}$. This condition for operating temperature in boiler is validated by journal. By obtaining simulation results, other related parameters such as heat flux, mass fraction of soot, mass fraction of oxygen can be determined using CFD analysis.

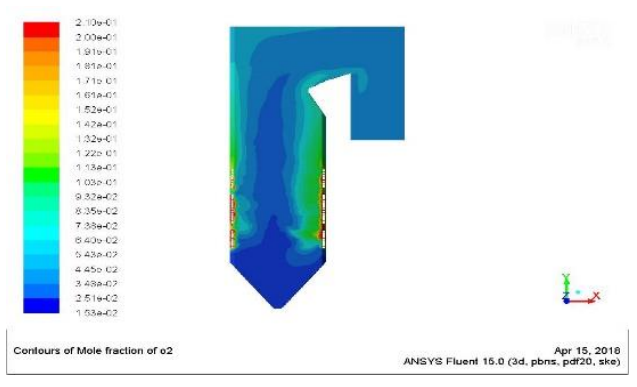

Fig. 3. Contours of Oxygen
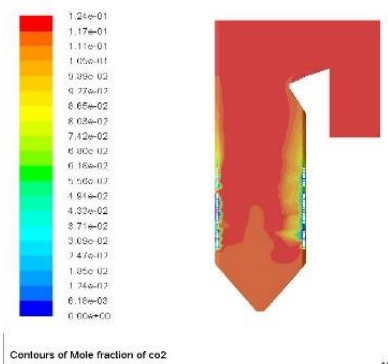

ANSYS Fluent 15.0 (3d, phns, pdpr 15,2010

Fig. 4. Contours of Carbon Dioxide

The validation of boiler is done by when contours of oxygen and carbon dioxide is obtained. For oxygen, there concentration of oxygen is high at boiler inlet which is represented by green and red colour as shown in Figure 3. The blue colour indicates low concentration of oxygen inside furnace as combustion takes place. On the other hand, contours of carbon dioxide shows the opposite of previous condition. The red colour shown in Figure 4 indicates high concentration of carbon dioxide inside furnace, and blue colour at boiler inlet. This suggests the boiler is operating in an optimal condition for simulation purpose.

\subsection{Particle Swarm Optimization}

Plant Swarm Optimization is an optimization tool used to study and learn from the scenario, while using it to solve optimization problems. [8] It is initialized by using a group of random particles (solutions), and then searches for optima by updating generations. In every iteration, each particle is updated by following best function value as shown in Table 5. In this case, specific parameter is chosen and used to find the best possible modal. For boiler modal, PSO modal serves as an optimization tool to find best function value that has minimal error as shown in Figure 5. 
TABLE 3. PSO results

\begin{tabular}{|c|c|c|c|c|}
\hline Parameter & Iteration & Swarm size & Range & BFV \\
\hline \multirow{9}{*}{$\begin{array}{c}\text { Mean Outlet } \\
\text { Flue Gas } \\
\text { Temperature }\end{array}$} & 50 & 10 & $160-170$ & 0.08345 \\
\hline & 50 & 5 & $160-165$ & 0.08111 \\
\hline & 50 & 5 & $165-170$ & 0.07957 \\
\hline & 100 & 10 & $160-170$ & 0.07955 \\
\hline & 100 & 5 & $160-165$ & 0.07867 \\
\hline & 100 & 5 & $165-170$ & 0.07999 \\
\hline & 200 & 10 & $160-170$ & 0.07959 \\
\hline & 200 & 5 & $160-165$ & 0.08533 \\
\hline & 200 & 5 & $165-170$ & 0.07943 \\
\hline \multirow{9}{*}{$\begin{array}{c}\text { Total } \\
\text { Secondary } \\
\text { Airflow }\end{array}$} & 50 & 100 & $680-780$ & 0.07031 \\
\hline & 50 & 50 & $680-730$ & 0.08931 \\
\hline & 50 & 50 & $730-780$ & 0.08829 \\
\hline & 100 & 100 & $680-780$ & 0.08657 \\
\hline & 100 & 50 & $680-730$ & 0.07975 \\
\hline & 100 & 50 & $730-780$ & 0.08768 \\
\hline & 200 & 100 & $680-780$ & 0.0875 \\
\hline & 200 & 50 & $680-730$ & 0.08796 \\
\hline & 200 & 50 & $730-780$ & 0.07999 \\
\hline
\end{tabular}

Optimization ended: relative change in the objective value

Optimization ended: relative change in the objective value particleswarm reached the value 0.079755 using 24960 function evaluations.

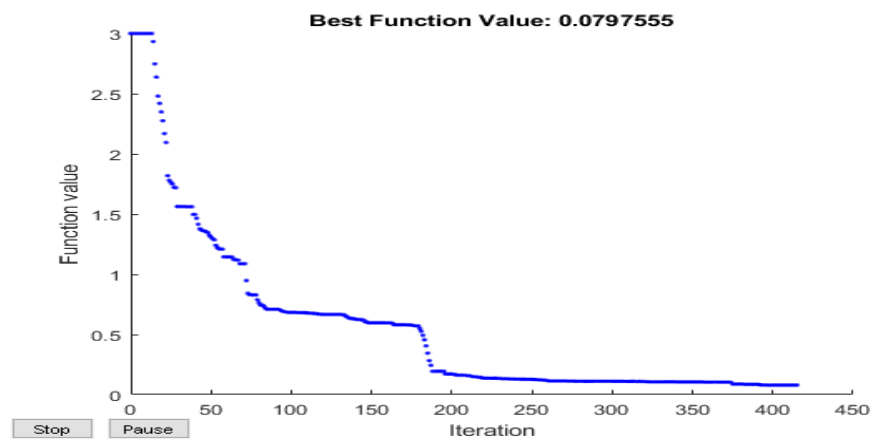

Fig. 5. Graph of best function value

The parameter with best value obtained from PSO modal is simulated back in CFD to ensure the parameter obtained is optimized in real time boiler condition.

\section{Conclusion}

This journal focuses on determining the optimized boiler parameter that affects the soot blowing operation in boiler. Firstly, the main parameters are identified to study the behaviour of boiler and how soot blowing activity affects the boiler performance. All parameters related to soot blowing activity is analysed and simulated in Computational Fluid Dynamics (CFD). CFD analysis is done by studying contours and values of pre-modelled boiler condition. All 
simulated values obtained is tabulated and analysed for understanding boiler modal. Then PSO is used as an optimization tool to optimize data obtained from plant, this provides a best function value with lowest error for each iteration. The parameter modal with lowest iteration is simulated in CFD to obtain the best soot blowing model.

The authors would like to thank Universiti Tenaga Nasional and Ministry of Higher Education Malaysia under MyBrain 15 scholarship scheme for the support. The authors would also like to thank TNB Janamanjung for research facilities and support.

\section{References}

1. Emerson Process Management, Ensure Efficient Sootblowing (2011)

2. Powerclean Performance. Intelligent Sootblowing (2011)

3. Kansas City Power \& Light (KCP\&L) Hawthorn Generating Station, Boosting Efficiency with a Sootblowing Optimization System (2012)

4. B.Pena, L.I Diez and E. Teruel, Applied Soft Computing, 11, 1657-1668, (2010)

5. S. B. Kumar, N.S. V. Gupta, International Journal of Engineering Research \& Technology, 2, 1265-1268, (2013).

6. E. Teruel, C. Cortes, L. I. Diez, I. Arauzo, Chemical Engineering Science, 60, 50355048, (2005).

7. B. Samik, International Journal of Emerging Technology and Advanced Engineering, 4, 628-630, (2014).

8. Xiaohui Hu, Particle Swarm Optimization Tutorial (2016) 